\title{
Editorial
}

\section{Palabras y cultura en la lengua del turismo}

\author{
Maria Vittoria Calvi
}

Università degli Studi di Milano (Italia)

El turismo está hecho de palabras: esta afirmación puede parecer descabellada si se piensa en la primacía de los elementos sensoriales en la experiencia turística, pero no lo es tanto si tenemos en cuenta la "intangibilidad" del producto turístico, en el que la comunicación verbal desempeña un papel no menos decisivo que otros factores materiales e inmateriales.

En primer lugar, cabe destacar la función de las palabras, no menos que de las imágenes, en la definición de la identidad de los destinos turísticos. El planteamiento constructivista hoy dominante en distintos sectores del saber - desde la sociología y la psicología a la antropología -, que concibe la identidad como una construcción dialéctica y no como una esencia, entronca con la visión de la lengua como acción social, que procede de los supuestos de la filosofía del lenguaje, en la línea de Austin y Searle. De ahí que los estudios sobre el binomio lengua e identidad hayan tenido gran desarrollo en el campo del análisis del discurso, que enmarca la lengua en el contexto social del que no solo es reflejo, sino también agente creador.

En el sector turístico se elabora una enorme cantidad de textos dirigidos al turista, en los que se describen y se promocionan los diferentes destinos: anuncios publicitarios, folletos, guías, etc., en papel o en formato digital, con una proporción variable de palabras e imágenes, en las que se condensan estereotipos, trazas de la memoria discursiva, citas de textos literarios, etc., así como otros elementos innovadores, en sintonía con las transformaciones que se llevan a cabo en el mundo del turismo, como la actual diversificación de sus tipologías (turismo activo, turismo cultural, turismo de aventura, turismo de salud y belleza, turismo enogastronómico, turismo musical, turismo religioso, turismo rural, etc.). Sobresale la preeminencia de los elementos evaluativos, como atestigua la abundancia, a veces abrumadora, de adjetivos calificativos. Asimismo, buena parte de estos textos desempeña una función orientadora de la mirada, como ya señalara Roland Barthes en su conocido estudio de la Guide bleu de España (Barthes, 1957/1999). Las secuencias directivas, en efecto, se alternan continuamente con las descriptivas, en la que se concentran los segmentos ponderativos.
Pero este modelo de comunicación top-down, en el que la lengua es funcional a una concepción del turismo como forma de control social (Dann, 1996), ha sido puesto en tela de jucio por la difusión de modelos más participativos, en los que el turista mismo se convierte en emisor de la comunicación. Por otro lado, se asiste a procesos de empowerment, que permiten una mayor participación de las comunidades locales en la gestión del turismo (cfr. el debate sobre el concepto de "comunidad" en el Especial sobre Turismo, Cultura y Sociedad: Tradición y Modernidad, Pasos, marzo de 2011).

No es tarea de los lingüistas evaluar el impacto social de estos fenómenos, pero sí lo es medir su influjo en la lengua del turismo, que se va abriendo al diálogo y la negociación. La actual fragmentación del género guía de viaje en múltiples variedades textuales limítrofes - desde la guía descriptiva tradicional, de carácter marcadamente directivo e impersonal, a los materiales promocionales y al testimonio directo de los viajeros, de impronta subjetiva - es buena prueba de ello.

En segundo lugar, la experiencia turística presupone el contacto con otras lenguas y otras variedades de la misma lengua. Aunque el turista pueda viajar inmerso en una especie de "burbuja" protectora, gracias a la mediación lingüística de los expertos (acompañantes, guías, etc.), desplazarse significa también cruzar fronteras lingüísticas internas y externas (Cronin, 2000), oír diferentes lenguas y acentos, e incluso experimentar la angustia que deriva del vacío comunicativo y del choque intercultural. De ahí la necesidad de transmitir al viajero la información relevante de la foma más clara posible, teniendo en cuenta que las barreras lingüísticas pueden verse acrecentadas por la distancia entre las culturas.

En el campo del turismo, se realiza una ingente labor traductora, en la que no siempre prima la calidad, debido también a la escasa inversión económica, que impide dirigirse a profesionales expertos. Como afirma Nobs: "El alto grado de profesionalidad que caracteriza la planificación y realización de las estrategias turísticas choca con la poca importancia que se le presta normalmente a la traducción de los folletos turísticos, mermando de este modo, en la 
última fase de la realización de proyectos muy valiosos, la eficacia de los mismos" (Nobs, 2006: 1).

En el turismo, la traducción es una delicada operación de mediación no solo lingüística sino también intercultural, que requiere competencias diversificadas de las variedades discursivas implicadas. En esta transferencia de conocimientos, la cultura cuenta decisivamente no solo en su acepción más elevada (historia del arte, productos del ingenio, etc.), sino también por lo que se refiere al conjunto de saberes implícitos que comparten los hablantes nativos. Además, traducir textos turísticos significa, a menudo, tomar decisiones sobre los elementos que se deben explicar o enfatizar, contribuyendo de forma decisiva a la construcción de las identidades turísticas.

El presente número especial de la revista Pasos recoge 13 artículos - 4 de los cuales redactados en inglés y los restantes en español -, elaborados por expertos de la lengua del turismo. Muchos de los autores participaron y participan conjuntamente en proyectos de investigación interuniversitarios sobre esta parcela lingüística, así como en el congreso Confines móviles. Lengua y cultura en el discurso del turismo, que se celebró en Milán en 2010 (véase Calvi, 2011). Este monográfico se sitúa en la estela de las discusiones propiciadas por aquel simposio, con el que comparte la voluntad de difundir los resultados de la investigación lingüística más allá del círculo restringido de los especialistas de esta disciplina.

El índice del volumen sigue el orden alfabético de los autores, de manera que cada lector podrá crear su propio itinerario de lectura. Son múltiples los lazos que ponen en relación los distintos trabajos; a continuación, voy a ensartarlos en un recorrido de presentación, siguiendo las líneas antes esbozadas.

Un grupo de artículos se centra en la comunicación promovida por la industria del turismo, mediante la cual se fraguan las identidades de los lugares. Graham M. S. Dann fija el paradigma de un nuevo escenario comunicativo en el que, a la voz de las instituciones y organizaciones turísticas, se añade la del turista, así como la de las comunidades involucradas, convirtiendo el monólogo en diálogo, o incluso 'triálogo' - diálogo entre tres voces -, desencadenando algunos cambios significativos en el lenguaje. El artículo plantea los posibles desarrollos de estas modalidades participativas, que, en la hipótesis más pesimista, podrían incluso potenciar el control ejercido por la industria turística.

En el ámbito de la comunicación institucional, Rosa María Rodríguez Abella analiza un amplio corpus de textos extraídos del sitio web de Turespaña, haciendo hincapié en las palabras clave, que atestiguan la voluntad de diversificar la oferta turística tradicional. Asimismo, Laura Mariottini se centra en la última campaña promovida por dicha institución, que muestra al turista como protagonista de unos vídeos promocionales, analizando la codificación multimodal del mensaje y las implicaturas conversacionales, es decir, los procedimientos inferenciales que permiten conectar la información visual con la verbal. Por su parte, Francisca Suau Jiménez destaca las estrategias utilizadas para situar al lector en el espacio textual de la promoción institucional, enfatizando la fuerza persuasiva del elemento interpersonal.

El llamado turista 2.0, más experto que nunca en la búsqueda de información, sabe explotar todos los canales comunicativos para satisfacer sus motivaciones específicas, que, por otra parte, la industria del turismo sabe interceptar y secundar. Giovanna Mapelli reflexiona sobre las estrategias lingüísticas empleadas para la promoción de nuevas tipologías de turismo a través de programas televisivos, con especial referencia al turismo solidario. Luisa Chierichetti se centra en el turismo musical como modalidad emergente, caracterizada por un alto nivel de compartición, adentrándose en la función desempeñada por las redes sociales en la remodelación de la lengua del turismo, que se 'conversacionaliza', adaptándose a las costumbres comunicativas de sus destinatarios.

La guía de viaje es el género 'fundacional' del turismo y su característica principal es el uso de las formas impersonales, pretendidamente objetivas; pero su parentesco con la literatura de viaje y la dimensión subjetiva del relato - central en el blog de viaje y en los diarios personales difundidos a través de las redes sociales - contribuyen a romper el esquema tradicional, haciendo de este género un potente instrumento ideológico. A estas clases textuales cercanas están dedicados cuatro artículos, que ofrecen también algunas calas en la diacronía. Donella Antelmi y Francesca Santulli escudriñan las analogías entre un corpus de libros de viaje y algunos apuntes de viajeros publicados en Internet, subrayando el papel clave de la narración subjetiva en la consolidación de la imagen turística de un lugar - la India en el caso analizado.

María Cristina Bordonaba Zabalza compara las diferentes estrategias utilizadas en cuatro guías de Navarra de las primeras décadas del siglo XX, en el momento del paso del modelo histórico-descriptivo al patrón más utilitario de la guía de tipo procedimental, con tendencia a la fijación de módulos evaluativos estereotipados.

Jordi Canals también pone de relieve las interferencias recíprocas entre las variedades textuales de la guía y del diario de viaje, con referencia a la obra de Pedro Antonio de Alarcón. Destaca la actitud crítica del escritor frente al incipiente turismo organizado y sus instrumentos - como la guía destinada a los viajeros -, pero también su curiosidad por este género, que favorece la hibridación estilística, anticipando la moderna narrativa de viaje.

Giovanni Garofalo analiza críticamente las estrategias discursivas empleadas en la Guía azul de Zaragoza para la construcción del destino turístico. En particular, observa cómo se va afirmando, a través de una red de presuposiciones y alusiones irónicas a la memoria discursiva, una nueva mitología, en la que se condensa el afán de autogobierno de la Comunidad.

En el ámbito de la traducción, David Katan hace hincapié en el choque lingüístico que puede acompañar la práctica del turismo y en la necesidad de hacer comprensibles las informaciones más relevantes, teniendo en cuenta las expectativas de los viajeros. El desajuste se ve 
claramente, por ejemplo, en el paso de una cultura turística basada en lo que hay que ver, dominante en un país como Italia, muy aferrado al patrimonio artístico cultural, a una visión centrada, más bien, en lo que se puede hacer, típica del mundo anglosajón.

Mirella Agorni insiste en el papel del traductor como mediador de conocimientos, pero también en su responsabilidad en la promoción turística, que se manifiesta en la elección de las estrategias persuasivas y las formas evaluativas. Asimismo, expresa el auspicio de que los agentes responsables de la promoción turística valoren adecuadamente la calidad de las traducciones que encomiendan.

Por último, el artículo de Julia Sanmartín afronta algunas cuestiones relativas al léxico, asimismo relevantes para la comunicación eficaz, ya que la precisión terminológica es fundamental para la comprensión de los servicios ofrecidos. En un sector tan crucial como la hostelería, y en el caso específico de la tipología de las habitaciones, se registra, sin embargo, una marcada variación denominativa, que no se ajusta ni a las normativas ni a los diccionarios existentes.

Este número especial se completa con algunas reseñas de volúmenes elaborados en el ámbito de diferentes proyectos de investigación sobre la lengua del turismo.

En resumidas cuentas, podemos afirmar que el análisis lingüístico de los textos turísticos pone de relieve una marcada polifonía, acorde con la tendencia participativa que hoy muestran los diferentes actores implicados en la práctica turística. También la industria del turismo se amolda a estas exigencias, modificando su lenguaje y adaptándolo a la negociación de identidades. Al mismo tiempo, se detectan algunas criticidades, sobre todo en el campo de la traducción, en el que no siempre se realiza de manera satisfactoria el complejo proceso de mediación intercultural exigido. En otra vertiente, también se destaca la poca atención por la normalización del léxico, con posibles repercusiones negativas en la transmisión de informaciones.

Tras esta breve panorámica, ha llegado el momento de los agradecimientos, que quiero dirigir, ante todo, a la redacción de la revista Pasos, y especialmente a su director, Agustín Santana Talavera, que ha aceptado incluir en la programación este recorrido entre las palabras del turismo. La edición del monográfico ha sido tarea compartida con Giovanna Mapelli, a quien agradezco la paciencia y el esmero con los que la ha llevado a cabo. Asimismo, quiero dar las gracias a Maria Giovanna Monterubbianesi, sin cuya colaboración no hubiéramos podido cumplir la labor.

\section{Bibliografía}

Barthes, Roland

1957/1999 Mitologías. México DF: Siglo XXI (original: Mythologies. Paris: Seuil)

Calvi, Maria Vittoria

2011 "Confines móviles. Lengua y cultura en el discurso del turismo". Pasos. Revista de turismo y patrimonio cultural, 9, 1: 193-195.
Cronin, Michael

2000 Across the Lines. Travel, Language, Translation. Cork: Cork University Press.

Dann, Graham M. S.

1996 The Language of Tourism. A Sociolinguistic Perspective. Oxon UK: CAB International.

Nobs, Marie-Louise

2006 La traducción de folletos turísticos. ¿Qué calidad demandan los turistas? Granada: Comares. 